\title{
Analisis Perbandingan Metode Interior Gateway Protocol RIP Dengan OSPF Pada Jaringan MPLS-VPLS
}

\author{
Yanuar Nurdiansyah', Nail Pratama ${ }^{2}$, Muhammad Ifantara Putra ${ }^{3}$, Muhammad Ali Sya'roni ${ }^{4}$ \\ 1,2,3,4 Laboratorium Sistem Informasi Geografis (SIG), Program Studi Teknologi Informasi, Fakultas Ilmu Komputer, \\ Universitas Jember (UNEJ) \\ yanuar_pssi@unej.ac.id,(nailprt07@gmail.com,ifantara82@gmail.com,malisya110100@gmail.com)
}

\begin{abstract}
Routing is a process for forwarding network packets from one network such as static routing and dynamic routing. This research will evaluate and implement protocols in dynamic routing such as RIP (Routing Information Protocol) and OSPF (Open Short Path First). What will later be simulated with GNS3, from this study will be obtained results For traceroute, OSPF is about $7 \%$ faster than RIP time, while for ping, OSPF is $5.9 \%$ faster than RIP and for traceroute in the topology the average result of the average traceroute time is 2.58 for RIP and 2.23 for OSPF.
\end{abstract}

Keyword: Open Short Path First, routing, GNS3, Routing Information Protocol

\section{Pendahuluan}

Pada umumnya banyak sekali metode untuk melakukan routing pada suatu jaringan. routing adalah proses menentukan jalur yang akan dilalui oleh paket. Routing dibagi menjadi 2 yakni routing static dan routing dinamis. Routing static yaitu ketika proses konfiigurasi dilakukan secara manual atau satu per satu oleh admin jaringan bagian konfigurasi. Sedangkan Dynamic routing yaitu ketika proses routing dan proses menentukan jalur sudah dilakukan oleh algoritm tertentu.

Dalam penerapannya sendiri tentu para administrator jaringan akan melakukan observasi dan evaluasi mana yang akan digunakan sebagai protokol agar nantinya routing akan bekerja dengan maksimal.Ada beberapa contoh protokol jaringan Dynamic routing seperti RIP (Routing Information Protocol) dan OSPF (Open Short Path First) [1][2]. Protokol jaringan tersebut memliliki keunggulan serta kelemahan masing-masing untuk itu kali ini penulis akan melakukan penelitian serta perhitungan untuk membandingkan mana yang lebih efektif dari beberapa protokol tersebut.

\section{Tinjauan Pustaka}

\subsection{Internet}

Internet (kependekan dari interconnection-networking) adalah seluruh jaringan komputer yang saling terhubung menggunakan standar sistem global Transmission Control Protocol/Internet Protocol Suite (TCP/IP) sebagai protokol pertukaran paket (packet switching communication protocol) untuk melayani miliaran pengguna di seluruh dunia. Rangkaian internet yang terbesar dinamakan Internet. Cara menghubungkan rangkaian dengan kaidah ini dinamakan internetworking ("antarjaringan") .

Pada awalnya merupakan jaringan komputer yang dibentuk oleh Departemen Pertahanan Amerika Serikat pada tahun 1969, melalui proyek ARPA yang disebut ARPANET (Advanced Research Project Agency Network), di mana mereka mendemonstrasikan bagaimana dengan hardware dan software komputer yang berbasis UNIX, kita bisa melakukan komunikasi dalam jarak yang tidak terhingga melalui saluran telepon.

\subsection{GNS3}

GNS3 adalah software simulasi jaringan komputer berbasis GUI yang mirip dengan Cisco Packet Tracer. Namun pada GNS3 memungkinkan simulasi jaringan yang komplek, karena menggunakan operating system asli dari perangkat jaringan seperti cisco dan juniper. Sehingga kita berada kondisi lebih nyata dalam mengkonfigurasi router langsung daripada di Cisco Packet Tracer. GNS3 adalah alat pelengkap yang sangat baik untuk laboratorium nyata bagi network engineer, administrator dan orang-orang yang ingin belajar untuk sertifikasi seperti Cisco CCNA, CCNP, CCIP dan CCIE serta Juniper JNCIA, JNCIS dan JNCIE. 
Fitur utama dari GNS3 adalah :

1) Desain kualitas tinggi dan topologi jaringan yang kompleks.

2) Mendukung banyak platform Cisco IOS router, IPS, PIX dan ASA firewall, JUNOS.

3) Simulasi Ethernet sederhana, ATM dan Frame Relay switch.

4) Koneksi jaringan simulasi ke dunia nyata!

5) Packet capture menggunakan Wireshark.

\subsection{VPLS}

VPLS adalah layanan virtual LAN yang bersifat pribadi, menghubungkan antara dua titik/node pada jaringan komputer yang dilakukan melalui sebuah tunnel (semacam terowongan). VPLS merupakan salah satu cara yang paling inovatif untuk meyediakan Ethernet VPNs, yang mengijinkan beberapa tempat dikoneksikan menggunakan sebuah jembatan (bridge) melalui sebuah jaringan yang diatur oleh penyedia layanan dengan dukungan MPLS. Seluruh klien menggunakan sebuah VPLS terlihat seolah-olah berada pada jaringan Local Area Network (LAN) yang sama, padahal mereka berada pada lokasi-lokasi yang berbeda.

VPLS menggunakan interface Ethernet kepada pelanggan, dimana mengijinkan penyediaan layanan yang cepat dan fleksibel. $\quad$ VPLS dapat menghubungkan beberapa kawasan geografi yang terpisah dengan cara menjembatani antara LAN dengan interface VPLS . Fitur VPLS memiliki segmen Local Area Network yang sama, walaupun secara kondisi geografisnya berjauhan [3].

Keuntungan dari VPLS adalah sebagai berikut:

1) Memiliki Throughput dengan bandwidth yang besar.

2) Dapat menekan biaya produksi, karena dapat menggunakan kabel Ethernet yang memiliki harga yang lebih murah jika dibandingkan dengan ATM, TDM, dan Frame relay.

3) Pelanggan dapat secara bebas mendesain IP address dan arsitektur Routing.

4) Mempunyai kemampuan untuk membawa traffic yang berasal dari non-ip.

5) Mempunyai kemampuan seperti MPLS [4].

Misal saya punya kantor cabang A,B,C.D yang letaknya saling berjauhan, dan setiap kantor cabang harus saling berkomunikasi, namun tidak boleh diakses dari luar, maka inilah alasan menggunakan VPLS.

\subsection{MPLS}

Multiprotocol Label Switching (atau disingkat MPLS) merupakan sebuah metode transmisi data yang menggunakan label untuk melakukan forwarding paket data [5][6]. Dengan penggunaan label ini maka pengiriman paket data akan dilakukan dalam kelompok-kelompok. Setiap kelompok yang ditransmisikan tidak terkait dengan kelompok lainnya. Dengan penggunaan label dalam transmisi data MPLS merupakan metode transmisi dengan beban proses yang minimal [7]

\subsection{Routing}

Routing adalah proses dimana suatu item dapat sampai ke tujuan dari satu lokasi ke lokasi lain. Beberapa contoh item yang dapat di-routing : mail, telepon call, dan data. Di dalam jaringan, Router adalah perangkat yang digunakan untuk melakukan routing trafik.

Konsep dasar routing ialah bahwa dalam jaringan WAN kita sering mengenal yang namanya TCP/IP (Transmission Control Protocol/ Internet Protocol) sebagai alamat sehingga pengiriman paket data dapat sampai ke alamat yang dituju (host tujuan). TCP/IP membagi tugas masing-masingmulai dari penerimaan paket data sampai pengiriman paket data dalam sistem sehingga jika terjadi permasalahan dalam pengiriman paket data dapat dipecahkan dengan baik. Berdasarkan pengiriman paket data routing dibedakan menjadi routing lansung dan routing tidak langsung.

\subsection{OSPF}

OSPF (Open Shortest Path First) merupakan sebuah routing protokol berjenis IGRP (InteriorGateway Routing Protocol) yang hanya dapat bekerja dalam jaringan internal suatu ogranisasi atau perusahaan. Jaringan internal maksudnya adalah jaringan di mana Anda masih memiliki hak untuk menggunakan, mengatur, dan memodifikasinya [8] [9] . Atau dengan kata lain, masih memiliki hak administrasi terhadap jaringan tersebut. Jika sudah tidak memiliki hak untuk menggunakan dan mengaturnya, maka jaringan tersebut dapat dikategorikan sebagai jaringan eksternal.

Selain itu, OSPF juga merupakan routing protokol yang berstandar terbuka. Maksudnya adalah routing protokol ini bukan ciptaan dari vendor manapun. Dengan demikian, siapapun dapat menggunakannya, perangkat manapun dapat kompatibel dengannya, dan di manapun routing protokol ini dapat 
diimplementasikan. OSPF merupakan routing protokol yang menggunakan konsep hirarki routing, artinya OSPF membagi-bagi jaringan menjadi beberapa tingkatan. Tingkatan-tingkatan ini diwujudkan dengan menggunakan sistem pengelompokan area [10] [11].

\subsection{RIP (Routing Information Protocol)}

Routing Information Protocol (RIP) adalah sebuah protokol routing dinamis yang digunakan dalam jaringan LAN (Local Area Network) dan WAN (Wide Area Network) [12]. Oleh karena itu protokol ini diklasifikasikan sebagai Interior Gateway Protocol (IGP). Protokol ini menggunakan algoritma DistanceVector Routing. Pertama kali didefinisikan dalam RFC 1058 (1988). Protokol ini telah dikembangkan beberapa kali, sehingga terciptalah RIP Versi 2 (RFC 2453) [13]. Kedua versi ini masih digunakan sampai sekarang, meskipun begitu secara teknis mereka telah dianggap usang oleh teknik-teknik yang lebih maju, seperti Open Shortest Path First (OSPF) dan protokol OSI IS-IS. RIP juga telah diadaptasi untuk digunakan dalam jaringan IPv6, yang dikenal sebagai standar RIPng (RIP Next Generation/ RIP generasi berikutnya), yang diterbitkan dalam RFC 2080 (1997).

\subsection{IGRP}

IGRP merupakan singkatan dari Inferior Gateway Protocol. Protocol ini dikembangkan pada pertengahan tahun 80-an oleh Cisco System Inc. Dengan tujuan utama untuk menyediakan protokol yang kuat untuk routing dalam sistem otonomi (Autonomous Systems). IGRP melakukan routing dengan berdasarkan jarak secara matematis. Karena itu, IGRP mempertimbangan bandwith, delay, beban dan keandalan sebelum mengambil keputusan rute mana yang akan ditempuh untuk mengalirkan data.

\section{Metode Penelitian}

Metode penelitian yang digunakan dalam penelitian ini dapat dilihat pada gambar 3.1

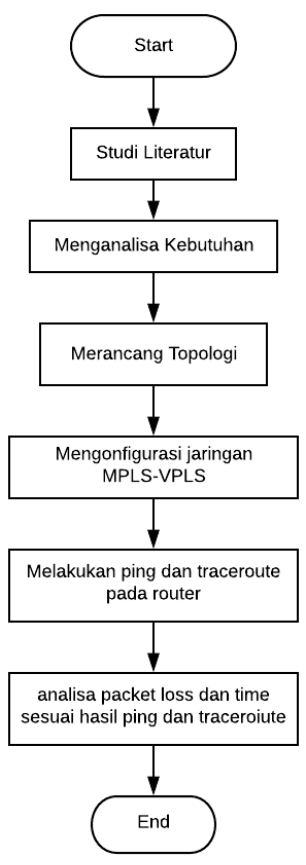

Gambar 3.1 Metode penelitian

\section{a. Studi Literatur}

Studi literatur adalah mengumpulkan data data, informasi, pengetahuan yang berkaitan dengan penelitian. Data, informasi, dan pengetahuan bersumber dari jurnal, website, buku, dan bertanya kepada dosen pembimbing. 


\section{b. Menganalisa kebutuhan}

Data, informasi,dan pengetahuan yang didapat pada studi literatur akan digunakan untuk menganalisa kebutuhan yang diperlukan dalam pembuatan simulasi jaringan, seperti virtualbox, virtual machine, GNS3, dsb.

\section{c. Merancang topologi}

Topologi dirancang di GNS3. Toplogi yang dirancang berupa topologi parallel (bercabang). Ada duua topologi yang dibuat, perbedaan diantara topologi tersebut hanyalah jenis IGP yang dipakai. Adapun topologi yang telah dibuat seperti gambar berikut

\section{d. Mengonvigurasi jaringan MPLS-VPLS}

Konfigurasi yang dilakukan sesuai dengan table 3.1:

Tabel 3.1. IP yang telah terkonfigurasi

\begin{tabular}{|c|c|c|c|}
\hline No & $\begin{array}{c}\text { Jenis } \\
\text { Router }\end{array}$ & $\begin{array}{c}\text { Interface } \\
\text { yang } \\
\text { terhubung }\end{array}$ & Alamat IP \\
\hline 1 & R1 & 2 & $16.16 .16 .1 / 24$ \\
\hline \multirow{4}{*}{2} & \multirow{4}{*}{$\mathrm{R} 2$} & 1 & - \\
\hline & & 3 & $23.23 .23 .2 / 24$ \\
\hline & & 5 & $25.25 .25 .2 / 24$ \\
\hline & & loopback & $2.2 .2 .2 / 32$ \\
\hline \multirow{3}{*}{3} & \multirow{3}{*}{$\mathrm{R} 3$} & 2 & $23.23 .23 .3 / 24$ \\
\hline & & 4 & $34.34 .34 .3 / 24$ \\
\hline & & loopback & 3.3.3.3/24 \\
\hline \multirow{4}{*}{4} & \multirow{4}{*}{ R4 } & 3 & $34.34 .34 .4 / 24$ \\
\hline & & 5 & $45.45 .45 .4 / 24$ \\
\hline & & 6 & - \\
\hline & & loopback & 4.4.4.4/32 \\
\hline \multirow{3}{*}{5} & \multirow{3}{*}{ R5 } & 2 & $25.25 .25 .5 / 24$ \\
\hline & & 4 & $45.45 .45 .5 / 24$ \\
\hline & & loopback & $5.5 .5 .5 / 32$ \\
\hline 6 & R6 & 4 & $16.16 .16 .6 / 24$ \\
\hline
\end{tabular}

\section{e. Melakukan ping dan traceroute pada router}

Ping dan traceroute untuk mengecek apakah antar router sudah terhubung atau tidak. Di tahap ini juga data data yang diperlukan untuk dianalisa diperoleh. Ping dan trace route di masing masing router dilkakukan sebanyak empat kali untuk mendapatkan hasil yang lebih akurat.

\section{f. Analisa paket loss dan time sesuai hasil ping dan traceroute.}

Dengan membandingkan paket loss dan time yang diperoleh masing masing ping dan traceroute.. 


\section{Hasil dan Pembahasan}

Table 4.1 merupakan hasil ping antara router:

Tabel 41. Hasil ping RIP

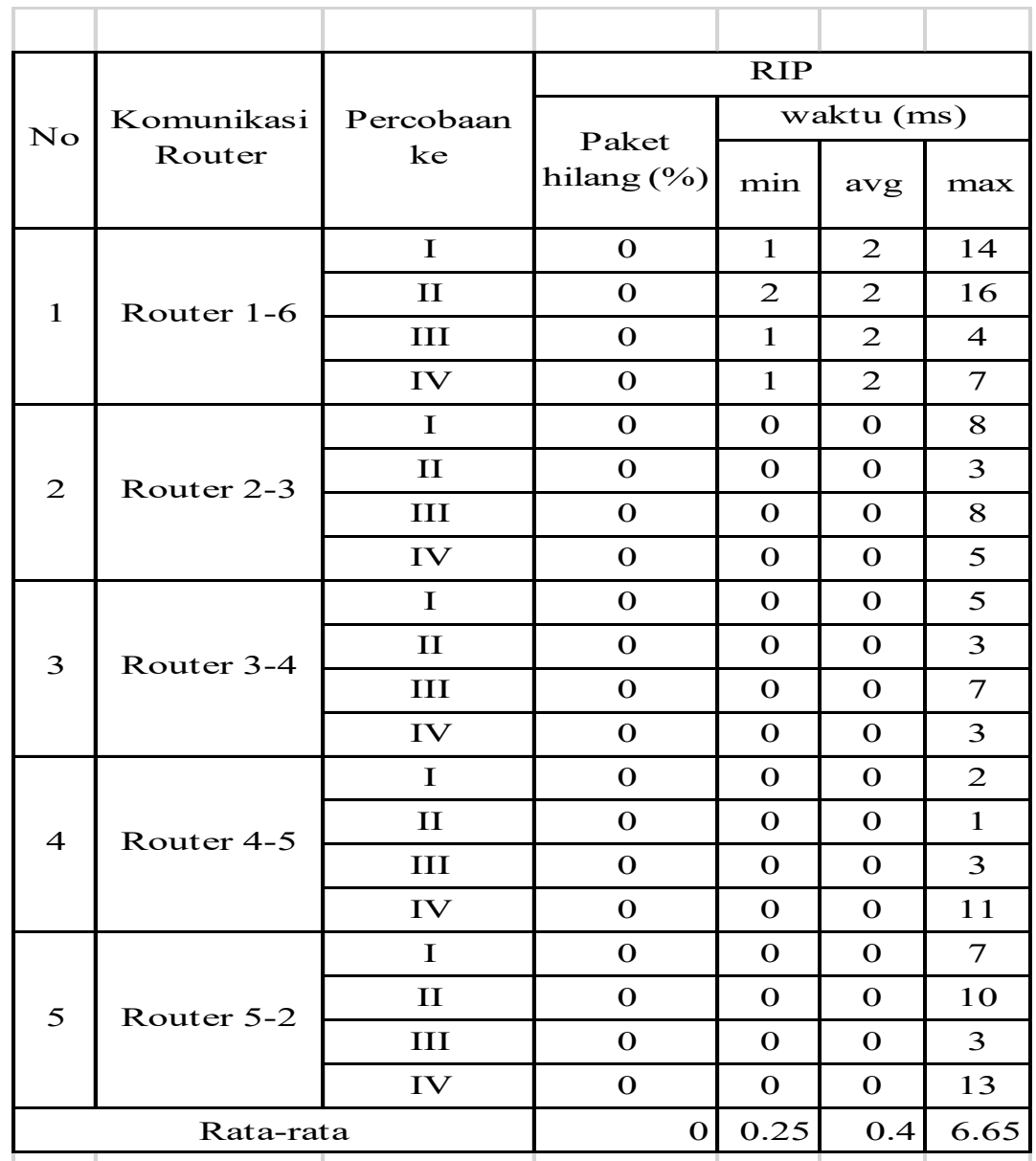


Tabel 4.2 . Hasil ping OSPF

\begin{tabular}{|c|c|c|c|c|c|c|}
\hline \multirow{3}{*}{ No } & \multirow{3}{*}{$\begin{array}{c}\text { Komunikasi } \\
\text { Router }\end{array}$} & \multirow{3}{*}{$\begin{array}{c}\text { Percobaan } \\
\text { ke }\end{array}$} & \multicolumn{4}{|c|}{ OSPF } \\
\hline & & & \multirow{2}{*}{$\begin{array}{c}\text { Paket } \\
\text { hilang (\%) }\end{array}$} & \multicolumn{3}{|c|}{ waktu (ms) } \\
\hline & & & & $\min$ & avg & $\max$ \\
\hline \multirow{4}{*}{1} & \multirow{4}{*}{ Router 1-6 } & I & 0 & 1 & 2 & 5 \\
\hline & & II & 0 & 1 & 2.1 & 4 \\
\hline & & III & 0 & 1 & 1 & 4 \\
\hline & & IV & 0 & 1 & 2 & 9 \\
\hline \multirow{4}{*}{2} & \multirow{4}{*}{ Router 2-3 } & I & 0 & 0 & 0 & 2 \\
\hline & & II & 0 & 0 & 0 & 3 \\
\hline & & III & 0 & 0 & 0 & 4 \\
\hline & & IV & 0 & 0 & 0 & 1 \\
\hline \multirow{4}{*}{3} & \multirow{4}{*}{ Router 3-4 } & I & 0 & 0 & 0 & 4 \\
\hline & & II & 0 & 0 & 0 & 2 \\
\hline & & III & 0 & 0 & 0 & 2 \\
\hline & & IV & 0 & 0 & 0 & 13 \\
\hline \multirow{4}{*}{4} & \multirow{4}{*}{ Router 4-5 } & I & 0 & 0 & 0 & 2 \\
\hline & & II & 0 & 0 & 0 & 5 \\
\hline & & III & 0 & 0 & 0 & 2 \\
\hline & & IV & 0 & 0 & 0 & 1 \\
\hline \multirow{4}{*}{5} & \multirow{4}{*}{ Router 5-2 } & I & 0 & 0 & 0 & 2 \\
\hline & & II & 0 & 0 & 0 & 2 \\
\hline & & III & 0 & 0 & 0 & 4 \\
\hline & & IV & 0 & 0 & 0 & 4 \\
\hline \multicolumn{3}{|c|}{ Rata-rata } & 0 & 0.2 & 0.36 & 3.75 \\
\hline
\end{tabular}

Dari hasil ping yang dilakukan pada topologi yang berbeda, yang pertama memakai IGP RIP sedangkan yang kedua memakai IGP OSPF. Dari table tersebut rata rata minimal waktu ping ialah $0.25 \mathrm{~ms}$ pada RIP dan $0.2 \mathrm{~ms}$ untuk OSPF. Rata rata dari avg waktu ping ialah $0.4 \mathrm{~ms}$ pada RIP dan 0.36 pada OSPF. Rata rata maksimal waktu ping ialah $6.65 \mathrm{~ms}$ untuk RIP dan $3.75 \mathrm{~ms}$ untuk OSPF. 
Tabel 2.3. Hasil traceroute pada topologi

\begin{tabular}{|c|c|c|c|c|c|c|c|c|}
\hline \multirow{2}{*}{ No } & \multirow{2}{*}{ IGP } & \multirow{2}{*}{$\begin{array}{c}\text { Komunikasi } \\
\text { Router }\end{array}$} & \multirow{2}{*}{$\begin{array}{c}\text { Percobaan } \\
\text { ke }\end{array}$} & \multirow{2}{*}{$\begin{array}{c}\text { Paket } \\
\text { hilang }(\%)\end{array}$} & \multicolumn{4}{|c|}{ Waktu } \\
\hline & & & & & akhir & avg & Tercepat & Terlambat \\
\hline \multirow{4}{*}{1} & \multirow{4}{*}{ RIP } & \multirow{4}{*}{ Router 1-6 } & I & 0 & 1.9 & 2.5 & 1.6 & 5.9 \\
\hline & & & II & 0 & 5.6 & 2.5 & 1.6 & 6.1 \\
\hline & & & III & 0 & 1.8 & 2.8 & 1.6 & 17.1 \\
\hline & & & IV & 0 & 2.2 & 2.5 & 1.6 & 9.4 \\
\hline \multirow{4}{*}{2} & \multirow{4}{*}{ OSPF } & \multirow{4}{*}{ Router 1-6 } & I & 0 & 1.9 & 2.3 & 1.4 & 10.2 \\
\hline & & & II & 0 & 2.1 & 2.1 & 1.5 & 6.7 \\
\hline & & & III & 0 & 2.2 & 2.1 & 1.4 & 7 \\
\hline & & & IV & 0 & 1.7 & 2.4 & 1.3 & 11.4 \\
\hline \multicolumn{9}{|c|}{ Rata rata } \\
\hline \multicolumn{4}{|c|}{ RIP } & 0 & 2.88 & 2.58 & 1.6 & 9.625 \\
\hline \multicolumn{4}{|c|}{ OSPF } & 0 & 1.98 & 2.23 & 1.4 & 8.825 \\
\hline
\end{tabular}

Dari hasil tracereoute table 4.3, diperoleh hasil rata rata dari avg waktu traceroute ialah 2.58 untuk RIP dan 2.23 untuk OSPF.

\section{Kesimpulan}

Hasil yang didapatkan pada ping dan traceroute menunjukkan bahwa menggunakan OSPF lebih cepat dibandingkan dengan menggunakan RIP. Untuk traceroute, OSPF lebih cepat sekitar 7\% dari waktu RIP, sedang untuk ping, OSPF lebih cepat $5.9 \%$ dari RIP.

\section{Daftar Pustaka}

[1] Alvyan, M., Trisnawan, P., \& Amron, K. Perbandingan Kinerja Protokol Routing RIP (Routing Information Protocol) dan OSPF (Open Shortest Path First) Berbasis IPv6. Jurnal Pengembangan Teknologi Informasi dan Ilmu Komputer, vol. 3, no. 10, p. 9644-9650, jan. 2020. ISSN 2548-964X

[2] M. S. Farouqui, V. Nigam and G. Gandhi, " Evolution of the Routing Protocols from RIP (1969) to OSPF (1998) ", ISSN: 2277 128X, IJARCSSE, vol. 4, no. 2, (2014).

[3] Fitriani, Devi. 2014. Implementasi dan Analisis Performansi Jaringan Multicast VPLS untuk Layanan Video Streaming, e-Proceeding of Engineering, 1(1): 171-180.

[4] Rick, G. (2003), MPLS Training Guide: Building Multi Protocol Label Switching Networks, Syngress Publishing 4. Febianto, Danang.2012.

[5] Rick, G. (2003), MPLS Training Guide: Building Multi Protocol Label Switching Networks, Syngress Publishing 4. Febianto, Danang.2012.

[6] Sofi, Umar B., dkk. 2015. Comparative Analysis of MPLS Layer 3vpn and MPLS Layer 2 VPN, IJCST, 3(3): 214-220. [6]. Syahputra, Muhammad Rizky. 2017.

[7] Harvianto, Farham. 2013. Analisis Jaringan MPLS VPN Menggunakan Bakchaul dengan Metode Overlapping, Jurnal, Universitas Budi Luhur: Jakarta Selatan.

[8] K. Kaur, S. Singh and R. Malhotra, "Design Of Open Shortest Path First Protocol -A Link State Protocol Using Opnet Modular", ISSN 2320-088X, IJCSMC, vol. 1, no. 1, (2012), pp.21-31.

[9] G. C. Nwalozie, V. N. Okorogu, A.C. Okafor and A.O. Umeh, "Evaluation And Implementation Of The Open Shortest Path First (OSPF) Routing Protocol", ISSN 2250-2459, ISO 9001:2008 Certified Journal, vol. 2, no. 12, (2012) 
[10] P. R. Gundalwar, D. V. N. Chavan, "Area Configuration and Link Failure Effect in IP Networks using OSPF Protocol", International Journal of Scientific and Research Publications, ISSN 2250-315, vol. 3, no. 4, (2013).

[11] P. R. Gundalwar, D. V. N. Chavan, "Area Configuration and Link Failure Effect in IP Networks using OSPF Protocol", International Journal of Scientific and Research Publications, ISSN 2250-315, vol. 3, no. 4, (2013).

[12] Jati, W.S., Nurwasito, H. dan Data, M. 2018. Perbandingan Kinerja Protocol Routing Open Shortest Path First (OSPF) dan Routing Information Protocol (RIP) Menggunakan Simulator Cisco Packet Tracer. Jurnal Pengembangan Teknologi Informasi dan Ilmu Komputer, [e-journal] 2(8). Tersedia melalui: Jurnal PTIIK [Diakses 02 Juli 2019]

[13] V. Vetriselvan, P. R. Patil and M. Mahendran, " Survey on the RIP, OSPF, EIGRP Routing Protocols ", International Journal of Computer Science and Information Technologies, vol. 5, no. 2, (2014), pp.1058- 1065. 